\title{
Familiarizing Students with Peer Assessment and Feedback Methods
}

\author{
Deler Singh, Gurvinder Kaur
}

\begin{abstract}
The paper examines the effectiveness of peer review and feedback during professional presentations in improving the participation and interpersonal communication skills of students. Existing research shows that such activities induce lifelong learning in students. The study has been conducted amongst the students from first year engineering programme who represented different engineering streams. The twin objectives of the study were to examine and reinforce learning in feedback skills. The objectives of peer assessment were introduced to the students. Rubrics for the assignment were explained to them thoroughly. The peer review was followed by an oral feedback by the students. The paper concludes with the discussion on challenges to peer assessment and ways to overcome these challenges.
\end{abstract}

Keywords : Lifelong learning, assessment, skill development, collaborative learning, higher education, professional development, self-assessment.

\section{INTRODUCTION}

Peer assessment may be defined as assessment of students' educational activities by other students of equal status. It involves numerous educational and skill development activities in which students are made to evaluate and provide feedback to their peers. Educational institutes across the globe have started encouraging peer assessment and other such teaching and learning interventions as they focus on enhanced students' participations/involvement and promise better learning. These methods promote in students the skills, such as better reflection on concepts, communication skills, team spirit and collaborative learning. Peer assessment has been viewed as a simulation of collaborative environment where students cooperate professionally with each other (Earl, 1986). Before formally starting with the evaluative sessions, however, the training in various modules is recommended. When students assume the role of the evaluator, earlier assigned to the instructor only, they show better understanding of the evaluation process and criteria involved. Students otherwise have shown

Revised Manuscript Received on September 15, 2019.

* Correspondence Author

Dr Deler Singh, Assistant Professor, School of Humanities and Social Sciences, Thapar Institute of Engineering and Technology, Patiala, Punjab, India.

Dr Gurvinder Kaur, Assistant Professor, School of Humanities and Social Sciences, Thapar Institute of Engineering and Technology, Patiala, Punjab, India. dissatisfaction with the grades/feedback they receive for their work, which is mostly due to insufficient knowledge about the evaluation parameters. Peers assessment leads to an increase in students' responsibility and autonomy and students find it challenging, helpful and beneficial as it provides them with opportunities to think and learn more and become more critical and structured (Falchikov, 1986). Peer assessment lets students have a say in the methods of learning and assessment and thereby increases their enthusiasm in such learning environments (Williams 1992).

Role of higher education in lifelong learning has been recognised by the academicians and researchers world over. Peer assessment equips a person in self-assessment as well. Students often undertake peer assessment in conjunction with formal self-assessment. It provides them opportunities to reflect on their own work and at the same times enrich their observation by having constructive and fruitful discussions about their own and their peers' work. Self-assessment is considered to be a necessary skill for lifelong learning (Boud 1990; 1995). Involvement of students in the process of peer-assessment is supported and recommended as it has been recorded to contribute greatly in inculcating the skills considered crucial for professional development such as autonomy, judgement and responsibility (Falchikov, 1988; Heron, 1981; Boud \& Prosser, 1980;). The assumption, that in real life also assessment of subordinates, peers, superiors and even themselves is an integral part of working environment, strengthens the introduction of peer assessment in the educational institutes (Oldfield \& MacAlpine, 1995). The idea is further endorsed by Kwan \& Leung (1996) that students should possess the skill of judging the performance of peers objectively and critically when they begin employment in any profession. Peer assessment has been recorded to be successful in terms of students' perception of learning benefits (Falchikov, 1986, 1995; Magin \& Churches, 1989; Mockford, 1994). There have been studies that report an improvement in students' performance as a result of peer assessment (Hendrickson et al., 1987; Stefani, 1994; Hughes \& Large, 1993). 
Despite the success of peer assessment in different teaching learning environments, as reported by various researches, people have shown their concerns about the effectiveness and reliability of the technique, especially for summative assessments. This is probably why, Boud (1989), a great supporter of peer assessment methods, cautions against using peer assessment for formal grading. Some studies have reported bias amongst students while judging their peers which may affect the entire evaluation process (Pond et al., 1995; Brindley \& Scoffield, 1998). Students, at times, tend to rank their friends higher than the others, while neglecting the merit altogether. Another concern regarding the effectiveness of peer assessment is that the students may not be able to evaluate the communication skills of their peers effectively. (Swanson et al., 1991; Van der Vleuten et al., 1991). Academicians who advocate peer assessment, however, have different opinions. They consider that when the students will come to know that peer assessment will be considered for final assessments, they will show a greater seriousness and commitment during peer assessment (Lejk et al., 1999). This commitment may otherwise be missing if students' ratings are used formatively only (Swanson et al, 1991).

\section{BACKGROUND OF THE STUDY}

The students of the undergraduate engineering programme in Thapar Institute of Engineering and Technology (TIET) study a course on Professional Communication in the very first year. This is a mandatory course for all streams of engineering. The overarching objective of the course is to prepare the young students for the campus placements which take place in the sixth/seventh semester. It is strategically placed in the first year so that the students have ample time and opportunities to practice the skills acquired through the course on Professional Communication.

The learning outcomes aim at effective communication skills, both individually as well as professionally. The nature of the course is primarily skill based. The theoretical foundations of communication are discussed in lecture classes and the tutorial classes are dedicated to skill development. This is done through assessable activities like public speaking (individual), presentations (paired), poster presentations (teams) and group discussion (group).

\section{CHALLENGES IN TRAINING AND ASSESSMENT OF SOFT SKILLS}

Nicol and Knight (2007) have termed the skills required in above activities as 'wicked competencies'. To elaborate, they define these as "very difficult to define because they can assume different contexts and they keep developing along entire lifetime". Hence, given the very nature of the skills, their training and evaluation pose high challenges. The other associated challenges that flow from the very nature of these competencies are: a) variation among individuals (socio-economic status, family, language, skills), can affect training structure.

b) Variations in assessors' background, attitude, skills etc. (lack of formal training in the area, terms of employment etc.)

One of the very important activities that the students are trained and evaluated on is Corporate Presentations/ Business Presentations/ Professional Presentations. This activity assesses students' written, spoken, and non-verbal skills at the same time. The students' enthusiasm for this activity is evidenced by a near $100 \%$ attendance from the time the module commences. The training on the module takes the following steps:

1) Formation of pairs (attempt to pair unfamiliar students).

2) Assignment of topic, structure of presentation and discussion.

3) Script submission and provision of feedback.

4) Revised scripts examined.

5) Training on non-verbal cues; do's and don'ts of audio-visual aids design provided.

6) Rubrics shared and discussed.

7) Presentation evaluation and feedback provided (visual, spoken and written).

The average marks lie between $60-70 \%$. As is evident, it is a rigorous process that takes up a lot of time and energy. Even after the rigour and seriousness attached to the activity, the following observations were made:

1) Lack of adherence by students to guidelines, particularly the structure.

2) Very less involvement of peers while presentations were in process.

\section{INTRODUCTION OF PEER REVIEW AND FEEDBACK DURING PRESENTATIONS}

Peer Reviews were introduced and the students were explained the objectives of the exercise. Teams had to give a joint review. A copy of the rubrics was given to the students to refer to while reviewing. Spoken feedback was also solicited on a voluntary basis. The review forms were handed over to the respective teams. This was an additional element that the students had to carry with them for the feedback sessions.

\section{RATIONALE FOR INTRODUCING PEER REVIEW AND FEEDBACK}

The conceptual rationale for Peer Review and Feedback is that it enables the students to play an active role in the management of their own learning. In their model of formative assessment and self-regulated learning, Macfarlane and Dick (2006) also contend that by commenting on the work of peers, students develop objectivity in relation to standards that can be transferred to their learning. This technique has received a 
lot of attention and support from the relevant literature (Topping 1998, 2007; Stephanie. J, \& Geoff I, 2000). A meta-analysis by Falchikov and Goldfinch (2000) found a very close resemblance of the student assessments to teacher assessments. Kollar and Fischer (2010) argue that 'peer assessment is an important component of 'a more participatory culture of learning' aiding 'the design of learning environments', as well as being, 'fundamentally a collaborative activity that occurs between at least two peers'. When students are facilitated to participate in some sort of assessment, it alters the power balance, at the same time encouraging control of their own learning. Along with this, students experience a development of their own learning; academically, emotionally as well as cognitively (Vickerman, 2009). Many researchers have listed the benefits of peer assessment as follows:

- It helps them to understand the academic standards of the module

- It helps them to understand assessment criteria and how they are applied to students' work.

- It helps them to understand alternative approaches to academic tasks.

- It develops their ability to make judgements and justify a point of view.

- It develops their ability to give constructive feedback to peers.

Peer assessments thus prepare them for autonomous learning by building their capacity to monitor their own progress rather than rely on a third party to do it (Bloxham and Boyd 2007).

From an educator's perspective, peer assessment has valuable and practical benefits. In the current context of Higher Education, where large classes are common, individual feedback and formative assessment have become increasingly difficult to deliver.

In Professional Presentation module, peer review was introduced with the intent of formative assessment and not summative assessment. Hence, it was not for grading but as a part of larger agenda that supports learning and measurement. This helps students to identify their strengths and weaknesses and also to focus on the areas that need remedial action. This is also supported by Simpson (2004).

\section{RESULTS}

After the completion of the activity, it was observed that the students scored a higher average of marks. Their involvement during the presentations improved significantly as was evident from the fact that more questions were asked by the students regarding the content and the reviews by the peers. In comparison to the previous batch, feedback scores on direct and indirect course learning objectives were much better. Feedback was also sought from the students. Since the objectives had been explained prior to introducing the strategy, most of the students expressed their solidarity with the achievement of the objectives. While observing that students can perceive peer assessment as a tool for reducing the marking workload of academics, Sher (2004) found that it freed academics to take on a more supportive and valuable tutorial/learning facilitator role. This encourages student/academic dialogue and the deepening of student learning beyond traditional methods of assessment. Peer assessment promotes a more complex cyclical model of learning (Nortcliffe et al., 2003), involving three interrelated processes (learning, assessment and feedback) and carried out by a group of people (students) with multiple roles. This is against the traditional mode of learning that is teacher centred.

\section{CONCLUSION}

Many issues have been cited by researchers as notes of caution while implementing the technique of peer review/ peer assessment. These issues, however, relate more to the summative aspect of assessment. In many Institutes/Universities, students' assessment is included in the grades, though the weightage may be subject to discretion of policy makers or course instructors. In summative peer assessment, accuracy of grades and validity of feedback is frequently questioned. Over-marking is an issue that is frequently observed, particularly if the groups are small and the assessors know each other (Vickerman, 2009; Patton, 2012; Kaufmann and Schunn 2011). In some responses recorded by the researchers, students expressed their preference for the facilitators to take responsibility for the assessment as they felt that their peers lacked the necessary expertise to grade them. Some students also perceived the assessment by their peers as inconsistent and unfair. Feelings of anxiety and lack of competence hence emerged as factors that have been reported by many researchers (Brown, Rust \& Gibbs, 1994). The above challenges come to the fore only when peer assessment is included in summative assessment. Its potential to enhance students' learning and feedback has never been in doubt. Successful peer learning and assessment require effective implementation and management. It needs to be embedded into the curriculum design. The students need to be involved in the exercise from the beginning of the course. The students should have knowledge about the assessment criteria. An effective rubric should be in place to enable the students to have a clear idea about assessment parameters. Finally, the students need to be trained in the art of providing effective feedback.

\section{REFERENCES}

1. Bloxham, S. and Boyd, P. (2007). Developing effective assessment in higher education: A practical guide. Berkshire: Open University Press. 
2. Boud, D. \& Prosser, M. (1980). Sharing responsibility: Staff-student cooperation in learning. British Journal of Educational Technology, 11, 24-35.

3. Boud, D. (1989). The role of self-assessment in student grading. Assessment and Evaluation in Higher Education, 14, 20-30.

4. Boud, D. (1990). Assessment and the promotion of academic values. Studies in Higher Education, 15(1), 101- 111.

5. Boud, D. (1995). Enhancing learning through self-assessment. London: Kogan Page.

6. Brindley, C. \& Scoffield, S. (1998). Peer assessment in undergraduate programmes. Teaching in Higher Education, 3, 79-89.

7. Brown, S., Rust, C. \& Gibbs, G. (1994). Strategies for diversifying assessment in higher education. Oxford: Oxford Centre for Staff Development.

8. Earl, S. E. (1986). Staff and peer assessment - measuring an individual's contribution to group performance. Assessment and Evaluation in Higher Education, 11(1), 60-69.

9. Falchikov, N. (1986). Product comparisons and process benefits of collaborative peer group and self-assessments. Assessment and Evaluation in Higher Education, 11(2), 146-166.

10. Falchikov, N. (1988). Self and peer assessment of a group project designed to promote the skills of capability. Programmed Learning and Educational Technology, 25, 327-339.

11. Goldfinch, J. \& Falchikov, N. (2000). Student peer assessment in higher education: A meta analysis comparing peer and teacher marks. Review of Educational Research, 70 (3), 287-322.

12. Hendrickson, J., Brady, M. \& Algozinne, B. (1987). Peer-mediated testing: The effects of an alternative testing procedure in higher education. Educational and Psychological Research, 7, 91-102.

13. Hanrahan, S.J. \& Isaacs, G. (2001). Assessing self and peer-assessment: The students' views. Higher Education Research \& Development, 20(1), 53-70.

14. Heron, J. (1981). Assessment revisited. In: D. Boud (Ed.), Developing student autonomy in learning (pp. 77-90). London: Kogan Page.

15. Hughes, I. \& Large, B. (1993). Staff and peer-group assessment of oral communication skills. Studies in Higher Education, 18, 379-385.

16. Kaufman, J.H. \& Schunn, C.D. (2011). Students' perceptions about peer assessment for writing: Their origin and impact on revision work. Instructional Science, 39(3), 387-406.

17. Knight, P. \& Page, A. (2007). The assessment of 'wicked' competences: A report to the Practice based Professional

18. Learning Centre. Retrieved from http://www.open.ac.uk/opencetl/sites/www.open.ac.uk.opencetl/files/file $\mathrm{s} / \mathrm{ecms}$

/web-content/knight-and-page-(2007)-The-assessment-of-wicked-compe tences.pdf

19. Kollar, I. \& Fischer, F. (2010). Peer assessment as collaborative learning: A cognitive perspective. Learning and Instruction, 20(4), 344-348.

20. Kwan, K. \& Leung, R. (1996). Tutor versus peer group assessment of student performance in a simulation training exercise. Assessment and Evaluation in Higher Education, 21, 3, 205-214.

21. Lejk, M., Wyvill, M. \& Farrow, S. (1999). Group assessment in systems analysis and design: A comparison of the performance of streamed and mixed-ability groups. Assessment and Evaluation in Higher Education, 24, 5-14.

22. Magin, D. \& Churches, A. (1989). Using self and peer assessment in teaching design. In: Proceedings of the 89th World Conference on Engineering Education for Advancing Technology, Institution of Engineers (pp. 640-644). Australia.

23. Mockford, C. (1994). The use of peer group review in the assessment of project work in higher education. Mentoring and Tutoring, 2, 45-52.

24. Nicol, D.J. \& Macfarlane-Dick, D. (2006). Formative assessment and self-regulated learning: A model and seven principles of good feedback practice. Studies in Higher Education, 31(2), 199-218.

25. Nortcliffe, A.L., Featherstone, S., Garrick, R. \& Swift, G. (2003). Supplemental instruction a higher level learning? In: W. Aung, M. Hoffmann, R. W. King, W. J. Ng \& L. M. S. Ruiz(Eds.). Engineering education and research: A chronicle of worldwide innovations (pp.30).Arlington, VA: iNEER.

26. Oldfield, K. \& Macalpine, M. (1995). Peer and self-assessment at tertiary level- an experiential report. Assessment and Evaluation in Higher Education, 20, 125-132.

27. Patton, C. (2012). Some kind of weird, evil experiment: Student perceptions of peer assessment. Assessment \& Evaluation in Higher Education, 37(6), 719-731.

28. Pond, K., Ul-Haq, R. \& Wade, W. (1995). Peer review: A precursor to peer assessment. Innovations in Education and Training International, 32 , 314-323.

29. Sher, W. (2004). Peer assessment in the design \& construction of a reinforced concrete Lintel. Centre for Education in the Built Environment Transactions, 1(2) 37-55.
30. Stefani, L. (1994). Peer, self and tutor assessment: Relative reliabilities. Studies in Higher Education, 19, 69-75.

31. Swanson, D., Case, S. \& Van Der Vleuten, C. (1991). Strategies for student assessment. In: D. Boud \& G. Feletti (Eds). The Challenge of Problem Based Learning. London: Kogan Page.

32. Topping, K.J. (1998). Peer assessment between students in colleges and universities. Review of Educational Research, 68(3), 249-276.

33. Topping, K. J. (2010). Methodological quandaries in studying process and outcomes in peer-assessment. Learning and Instruction, 20(4), 339-343.

34. Vickerman, P. (2009). Student perspectives on formative peer assessment: An attempt to deepen learning?. Assessment \& Evaluation in Higher Education, 34(2), 221-230.

35. Williams, E. (1992). Student attitudes towards approaches to learning and assessment. Assessment and Evaluation in Higher Education, I7 (1), $45-58$. 